\title{
PERANCANGAN KOMIK STRIP ONLINE SEBAGAI MEDIA INTERAKTIF PEMBELAJARAN REMAJA DI KOTA BANDUNG
}

\author{
Muhammad Adam Permana ${ }^{1}$, Hadah Muallimah ${ }^{2}$ \\ Program Studi Desain Komunikasi Visual ${ }^{1,2}$ \\ Sekolah Tinggi Teknologi Bandung ${ }^{1,2}$ \\ adamp170898@gmail.com ${ }^{1}$, hadahmuallimah@sttbandung.ac.id ${ }^{2}$
}

\begin{abstract}
Abstrak
Pubertas merupakan masa peralihan dari masa kanak-kanak ke masa dewasa meliputi perubahan biologis, perubahan psikologis dan perubahan social. Dimana pada masa tersebut mereka sering kali mengalami hambatan dan gangguan. Untuk mengatasi permasalahan maka diperlukan sebuah media informasi yang dapat menjawab permasalah tersebut. Adapun metode penelitian yang dipakai dalam perancangan adalah metode kuantitatif. Dengan cara melakukan observasi melalui kuisioner yang disebarkan kepada remaja usia 10-16 tahun di kota Bandung. Dari hasil tersebut maka dipilihlah komik strip online sebagai media perancagan. Yang diharapkan dapat menarik dan menambah wawasan remaja tentang hal-hal seputar pubertas dan bagaimana cara menjalani masa perubahan.
\end{abstract}

Kata Kunci : Pubertas, Komik Strip, Remaja, Online

\begin{abstract}
Puberty is a period of transition from childhood to adulthood. Includes biological changes, psychological changes and social changes. Where at that time they often experienced obstacles and disturbances. To overcome these problems, we need an information media that can answer these problems. The research method used in the design is a quantitative method. By doing observations through questionnaires distributed to adolescents aged 10-16 years in the city of Bandung. From these results, the online comic strip was chosen as the design medium. Which is expected to be able to attract and add insight to teenagers about things about puberty and how to go through a period of change.

Keywords: Puberty, Comics, Teens, Online
\end{abstract}

\section{PENDAHULUAN}

Masa remaja merupakan masa transisi atau peralihan dari masa kanak-kanak menuju masa dewasa yang ditandai dengan adanya perubahan mulai dari bentuk tubuh, penampilan diri, sikap kepemilikan, sikap social dan minat seks. Menurut WHO (2018) dikatakan usia remaja antara 10- 19 tahun. Akan tetapi berdasarkan penggolongan usia, masa remaja terbagi menjadi tiga yakni masa remaja awal (10-13 tahun ), masa remaja tengah (14-16 tahun), dan masa remaja akhir (17- 19 tahun) (Poltekes Depkes Jakarta, 2010: 1) . Jumlah usia tersebut tentunya relatife cukup besar khususnya di kota Bandung. Menurut BPS (2010) Jumlah penduduk di di kota Bandung mencapai 2,507888 jiwa, dari jumlah tersebut dibagi menjadi beberapa kategori untuk rentan usia yang pertama umur 5-9 tahun mencapai 18.9958 jiwa $(7,48 \%)$, umur 10-14 tahun mencapai 17.0126 (6.78\%) dan umur 15-19 tahun mencapai $21.4786(8,56)$, Jumlah data tersebut tentunya cukup besar, Terutama pada usia 11-16 tahun. Dimana pada usia tersebut mereka mengalami masa pubertas. Masa pubertas merupakan masa dimana bergejolaknya hormon dalam tubuh. yang berdampak pada pertumbuhan fisik yang sangat cepat yang meliputi perubahan porsi tubuh dan perkembangan seks primer, yang tidak jarang menimbulkan kecemasan dan kebingungan. Berbagai perubahan tersebut terkadang ada yang dapat dilalui oleh remaja dengan baik dan ada juga sebagain remaja yang mengalami hambatan dan gangguan dalam proses perkembangannya. Adapun porses tahap perkembangan hendaknya dapat memberikan pemahaman dan informasi yang berguna bagi remaja, akan tetapi remaja sering kali mengalami hambatan dalam mencari informasi tersebut padahal pengetahuan dan pemahaman tentang pubertas merupakan informasi awal yang sangat penting diketahui. Karena perubahan pubertas yang dialami oleh remaja akan mempengaruhi berbagai perkembangan lainya seperti perkembangan kognitif, moral, sosial, dan religius.

Sehingga berdasarkan masalah tersebut maka diperlukan sebuah media pembelajaran, yang bertujuan sebagai alat bantu yang dapat berguna mengatasi masalah tersebut. Adapun media pembelajaran yang dipilih target audience berdasarkan data kuesioner yang disebar adalah komik. Komik merupakan salah satu media saat ini yang sedang banyak di gandrungi oleh masyarakat [1]. Selain sifatnya yang menghibur komik juga dapat menjadi sebuah inovasi baru dalam pembelajaran yang tentunya dapat digunakan untuk mengatasi permasalahan dalam memahami suatu materi pelajaran. Sehingga komik juga tidak hanya dapat meningkatkan minat baca remaja, tapi juga dapat memotivasi remaja terhadap materi pembelajaran yang diajarkan, dengan harapan akan memberikan dampak yang positif terhadap hasil belajar.

Adapun komik yang di rancang adalah komik strip online. Diharapkan remaja nantinya dapat belajar sendiri tanpa harus melalui bimbingan orang lain, dan dapat melakukannya kapan saja dan dimana saja, dapat mengontrol laju kecepatan belajarnya sendiri, dan juga dapat memberikan respon dan tanggapan baik berupa jawaban, pilihan, keputusan, dan lain-lain, terhadap topik yang dipelajari. Dengan adanya proses ini, remaja, dapat memiliki ikatan yang lebih mendalam terhadap topik yang dipelajari dari pada hanya mendengarkan dari pihak ketiga. Dengan ikatan inilah, remaja diharapkan akan lebih mengerti dan memahami tentang topik pembelajaran.

Adapun pendistribusian komik strip akan di lakukan secara online melalui aplikasi instagram yang tentunya akan menarik minat remaja, terutama remaja di kota bandung yang memiliki jumlah populasi besar. Yang dimana setiap 
remajanya saat ini sudah sangat tergantung dengan handphone yang telah menjadi benda wajib yang dimiliki oleh setiap remaja. Benda tersebut akan dianggap lebih baik, lebih menarik, lebih praktis dan dapat meninggikan prestige. Oleh sebab itu perancangan ini di buat sebagai sebuah media pembelajaran untuk remaja yang dapat menjadi salah satu solusi untuk meningkatkan minat remaja tentang pubertas dengan cara yang benar dan menarik. Cara yang menarik ditempuh melalui media komik strip yang edukasi yang dekat dengan kehidupan dan kebiasaan mereka.

\section{LANDASAN TEORI}

\section{Remaja}

Masa remaja (usia 11 - 20 tahun) adalah masa yang khusus dan penting, karena merupakan periode pematangan organ reproduksi manusia. Masa remaja disebut juga masa pubertas, merupakan masa transisi yang unik ditandai dengan berbagai perubahan fisik, emosi dan psikis[2]. Sedangkan menurut KBBI, remaja merupakan masa dimana seseorang itu mulai dewasa[3]. Dapat disimpulkan bahwa remaja merupakan masa dimana seseorang berubah dari masa kanak-kanak lalu beranjak menuju dewasa dan banyak perubahan yg terjadi ditandai dengan masa pubertas tiap individunya.

\section{Komik}

Menurut Kamus Besar Bahasa Indonesia, pengertian dari komik adalah cerita bergambar (dalam majalah, surat kabar, atau berbentuk buku) yang umumnya mudah dicerna dan lucu [4]. Pendapat lain mengemukakan bahwa Komik adalah media komunikasi visual yang berisi suatu informasi, ide, pesan yang dituangkan ke dalam gambar semenarik mungkin. Sehingga dapat ditarik kesimpulan dari komik adalah suatu media yang dapat menjadi wadah atau fasilitas seseorang untuk memberikan informasi secara menarik[5].

\section{Media Interaktif}

Media interaktif biasanya mengacu pada produk dan layanan digital pada sistem berbasis komputer yang merespon tindakan pengguna dengan menyajikan konten seperti teks, gambar bergerak, animasi, video, audio, dan video game[6]. Dengan menggunakan media yang interaktif dapat dijadikan strategi untuk menyampaikan suatu informasi dengan tepat sasaran.

\section{PEMBAHASAN}

\section{Media Utama}

Komik merupakan salah satu bentuk media komunikasi visual yang memiliki kekuatan untuk menyampaikan informasi secara populer dan mudah dipahami dalam hal penyampaian pesan berupa gambar dan teks. Komik ini juga bermanfaat dalam menyampaikan pesan yang bersifat edukatif, sosial dan simpatik kepada pembaca. Komik strip ini ditampilkan dengan gambar, teks dan narasi karena remaja lebih cenderung menangkap informasi melalui gambar dan tulisan yang menarik perhatian. Penulis mengemasnya semenarik mungkin dan menyisipkan pesan moral di dalamnya.

\section{Pendekatan Verbal}

Konsep verbal yang digunakan dalam komik strip puberstory ini adalah penggunaan bahasa sehari-hari anak muda dibuat agar mudah untuk dimengeri dan dipahami oleh target audience, yaitu generasi muda atau remaja. Penggunaan bahasa dalam desain dibuat sederhana, lugas, tidak berbelit-belit dalam kata-kata tetapi pesan dan maknanya yang dikandung tetap bisa tersampaikan dengan baik, penulis juga mendeskripsikan karakter anak muda masa kini yang unik dan bergaya, agar tidak terlihat membosankan.

3. Pendekatan Visual

a. Format Desain

Setelah menentukan konsep verbal, langkah selanjutnya adalah membuat konsep visual. Awal dari pembuatan komik strip adalah membuat sketsa dengan menggunakan pensil pada kertas gambar. Dari sketsa manual kemudian dipindai menggunakan alat scanner. Setelah melalui proses pindai, hasil dari proses pindai akan di ubah dalam bentuk jpeg, setelah itu masuk ke tahap digital yang nantinya akan digambar ulang menggunakan software Adobe Illustrator Cc 2019. Kemudian hasil sketsa akan pertegas dengan menaikkan kontras agar hasil sketsa lebih jelas, tanpa menghilangkan sketsa dasar yang dibuat. Setelah melalui proses tersebut kemudian hasil sketsa akan masuk ke tahap pewarnaan yang akan dibuat berdasarkan referensi data yang telah di proleh.

b. Gambar

Dalam perancangan komik digital ini menggunakan pendekatan berupa gaya gambar cartoon style dengan menggunakan gambar lucu dan sederhana yang mengikuti trend saat ini. Alasan penggunaan gaya gambar cartoon style adalah karena gaya kartun dapat menjangkau demografi sasaran yang sangat luas, misalnya seperti komik gung, komik kezel dan lieur yang memiliki gambar yang khas dan menarik. Dengan adanya gaya gambar 
kartun ini diharapkan dapat menarik minat baca remaja.

c. Warna

Warna merupakan elemen penting bagi sebuah desain selain berfungsi sebagai bagian dari elemen estetis, warna juga memegang peranan penting dalam perancangan ini komik strip ini karena ditujukan untuk remaja laki-laki dan perempuan, maka untuk pewarnaan juga akan dibedakan sesuai dengan jenis gender mereka. Untuk warna laki-laki akan menonjolkan warna maskulin seperti warna biru, sedangkan untuk bagian perempuan akan menonjolkan warna feminim seperti warna pink. Sedangkan untuk background dan warna pada kulit karakter, dipilih warna cerah agar gambar tidak terlihat kaku.Teknik pewarnaan dalam media komik strip ini akan menggunakan teknik blok, yang ditujukan agar ilustrasi tidak terlihat rumit, sehingga pengguna dapat memusatkan perhatian pada informasi yang diberikan

d. Font

Untuk penggunaan font pada teks percakapan komik strip dipilihlah Comic Sans yang diambil sesuai saran audience.adapun keunggulan font Comic Sans ini memiliki garis seimbang tidak terlalu tebal dan tidak terlalu tipis sehingga cocok sekali untuk memperkuat cerita yang terdapat dalam komik strip adapun untuk font impact digunakan dalam isi komik. ditujukan sebagai penjelas suatu peristiwa. pemilihan huruf ini dikarenakan font impact dapat memberikan kesan dramatis serta dinamis. Berikut adalah font yang digunakan dan contoh penerapannya pada komik strip:

4. Final Desain

a. Media Utama

a. Isi Komik
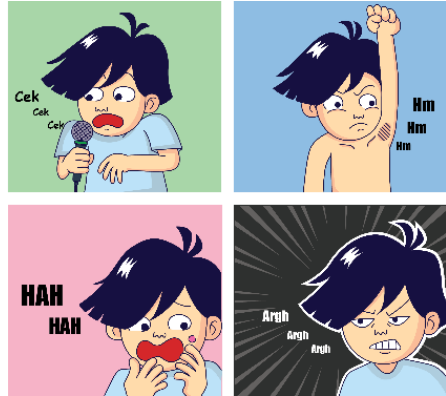

Gambar 1. Prolog "Pengenalan pubertas"

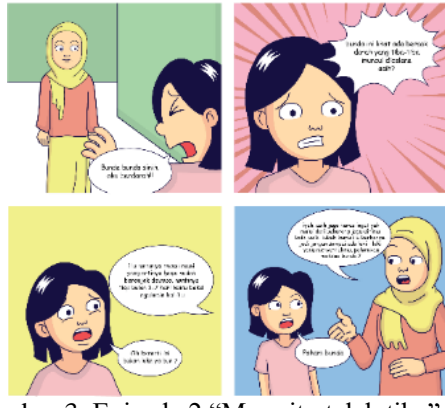

Gambar 3. Episode 2 "Masa itu telah tiba"

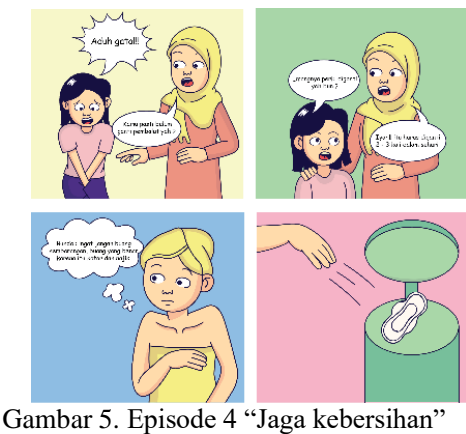

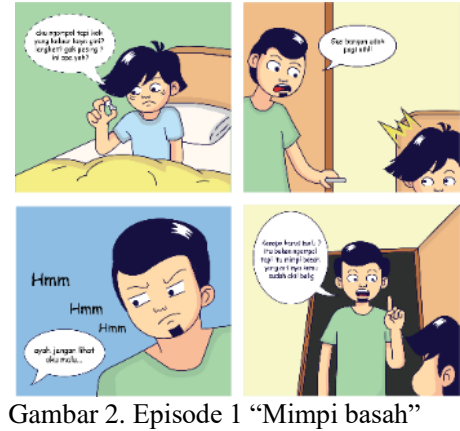
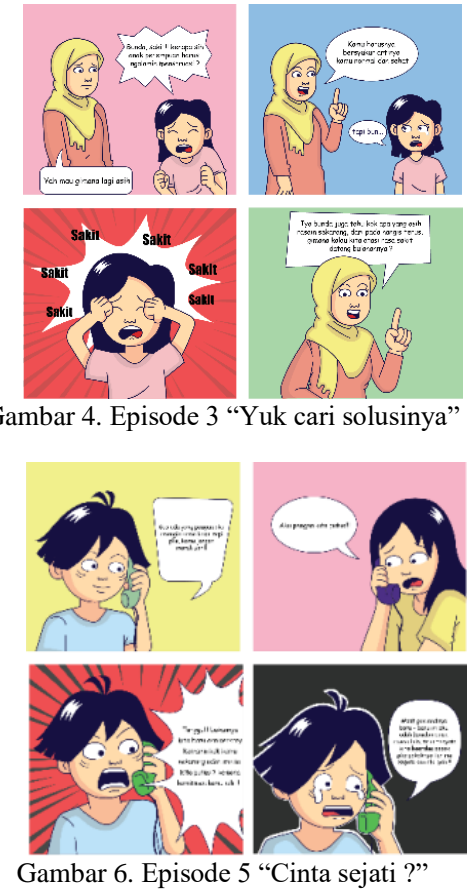
KREATIF(Jurnal Karya Tulis, Rupa, Eksperimental dan Inovatif)

Vol. 04 No. 01 Juni 2022

P-ISSN: 2746-4369 || E-ISSN: 2714-9978

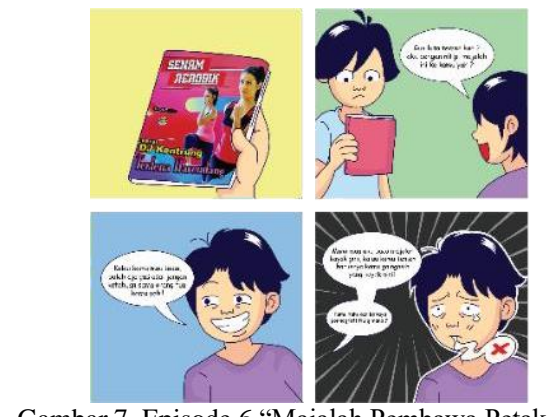

Gambar 7. Episode 6 "Majalah Pembawa Petaka

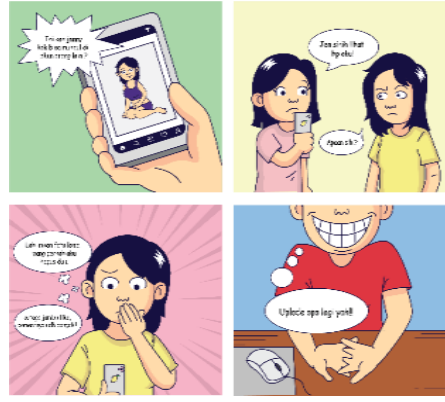

Gambar 9. Episode 8 "Bahaya Sexting"
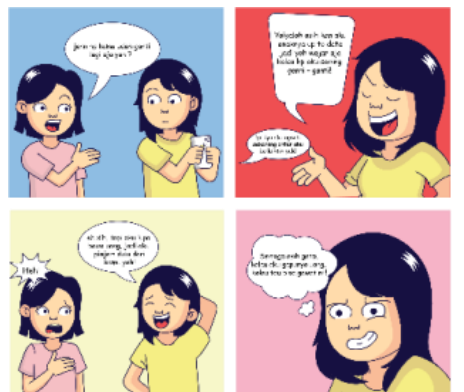

Gambar 11. Episode 10 "Demi Gaya"

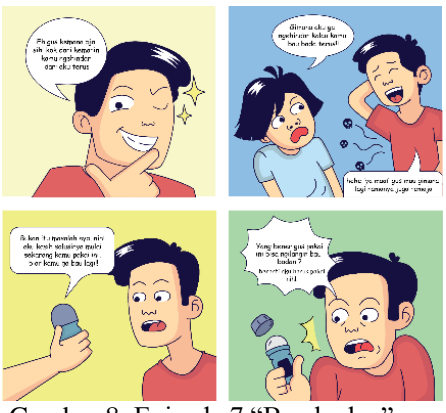

Gambar 8. Episode 7 "Bau badan"
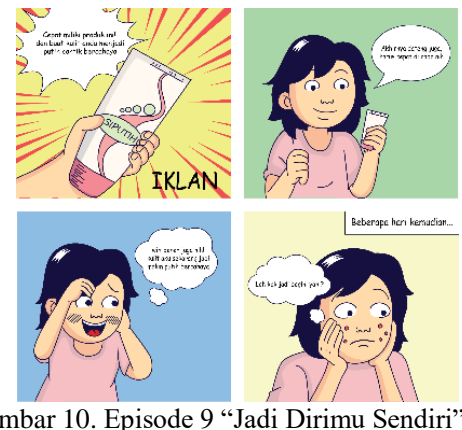

Gambar 10. Episode 9 “Jadi Dirimu Sendiri”
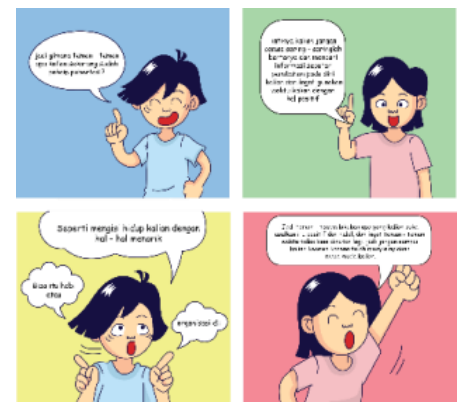

Gambar 12. Epilog "Manfaatkan Waktumu”

a. Media Pendukung
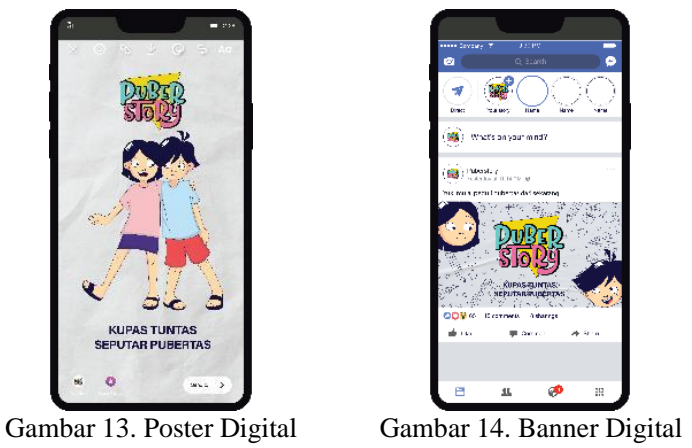

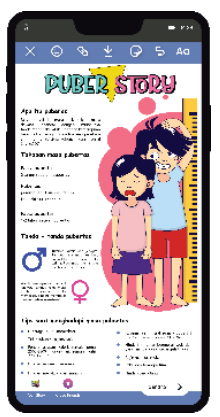

Gambar 15. Infografis

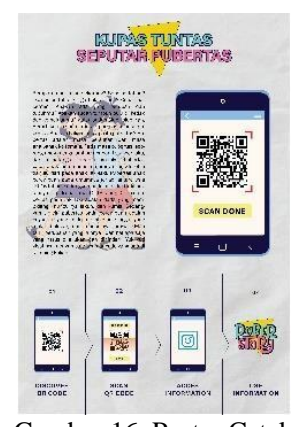

Gambar 16. Poster Cetak 


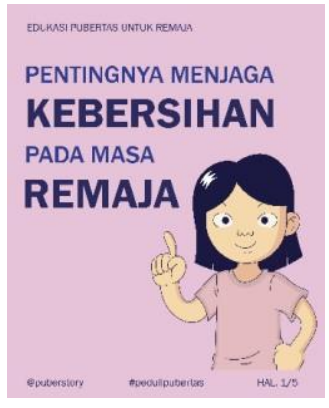

Gambar 17. Feed Instagram



Gambar 18. Komik Cetak

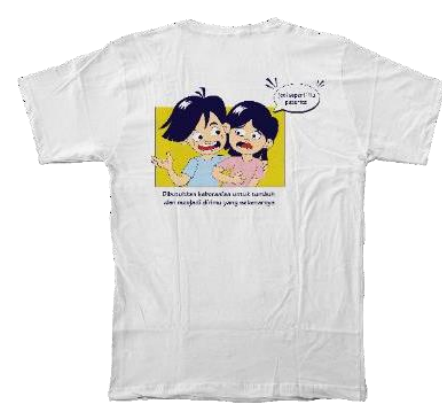

Gambar 19. Kaos

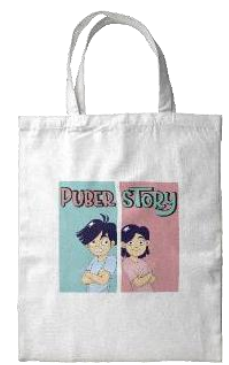

Gambar 20. Totebag

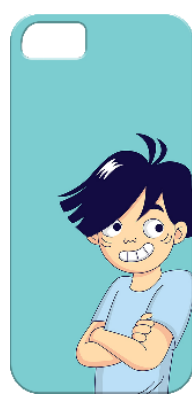

Gambar 21. Case Handphone

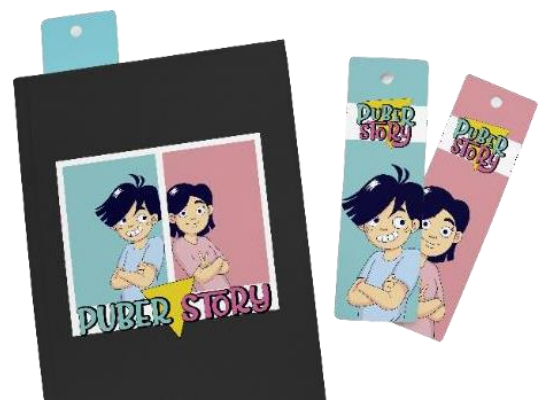

Gambar 22. Note Book

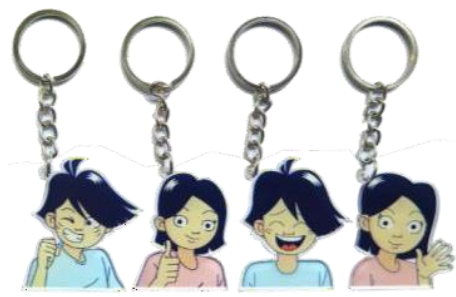

Gambar 23. Gantungan Kunci

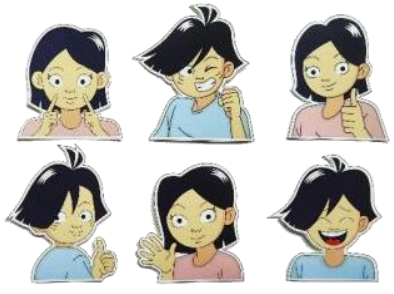

Gambar 24. Sticker

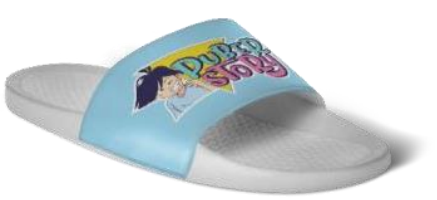

Gambar 25. Sendal Slip

\section{KESIMPULAN}

Pembelajaran tentang pubertas merupakan hal yang penting bagi remaja dalam mendukung pertumbuhannya. Namun, mereka seringkali mengalami kesulitan atau hambatan ketika mencari informasi tentang pubertas pada diri mereka sendiri. Maka untuk itu diperlukan sebuaah pendekatan kreatif salah satunya melalui pendidikan komik strip online. Sehingga cerita ilustrasi yang dibuat pada komik strip mampu menyampaikan informasi yang jelas, komunikatif, dan menarik. Sehingga remaja mampu mendapatkan pembelajaran yang maksimal tentang pubertas dan juga mampu mengatasi masalah serta menambah pengetahuannya. Melalui pembuatan komik strip online ini, mereka juga bisa menjadikan komik strip online ini sebagai sarana refreshing karena bentuk olah cerita yang mengalir dan santai. Untuk itu, buku ini diharapkan dapat menjadi panduan ringan bagi remaja untuk berpikir positif, dan menyadari siapa dirinya.

\section{REFERENSI}

[1] Oktaviano, Tino. 2016. "Komik Lokal Banyak Digandrungi Masyarakat." Aktual.Com. 2016. https://aktual.com/komik-lokal-banyakdigandrungi-masyarakat/

[2] Aisyaroh, Noveri, S. P. P. D. I. Kebidanan, and F. I. K. Unissula. "Kesehatan Reproduksi Remaja." Jurnal Majalah Ilmiah Sultan Agung. Universitas Sultan Agung (2010).

[3] https://kbbi.kemdikbud.go.id/entri/remaja, diakses 13 April 2021.

[4] https://kbbi.kemdikbud.go.id/entri/komik, diakses 13 April 2021.

[5] Siregar, Helmi Fauzi, Yustria Handika Siregar, and Melani Melani. "Perancangan Aplikasi Komik Hadist Berbasis Multimedia." JurTI (Jurnal Teknologi Informasi) 2.2 (2018): 113-121.

[6] https://id.wikipedia.org/wiki/Media_interaktif, diakses 13 April 2021 